\title{
OPERATIONAL SHIPPING INTELLIGENCE THROUGH DISTRIBUTED CLOUD COMPUTING
}

\author{
Dragos Sebastian CRISTEA ${ }^{1}$, Liliana Mihaela MOGA ${ }^{2}$, \\ Mihaela NECULITA ${ }^{3}$, Olegas PRENTKOVSKIS ${ }^{4}$, \\ Khalil MD NOR ${ }^{5}$, Abbas MARDANI ${ }^{6}$ \\ 1, 2, ${ }^{3}$ Faculty of Economics and Business Administration, Dunarea de Jos University of Galati, \\ 47, Domneasca Street, 800008 Galati, Romania \\ ${ }^{4}$ Department of Mobile Machinery and Railway Transport, Vilnius Gediminas \\ Technical University, Plytinès g. 27, LT-10105 Vilnius, Lithuania \\ ${ }^{5,6}$ Faculty of Management, University of Technology Malaysia, 81310 Skudai Johor, Malaysia \\ E-mails: ${ }^{1}$ dragoscristea@yahoo.com; ${ }^{2}$ liliana.moga@gmail.com; \\ 3neculitam@yahoo.fr; ${ }^{4}$ olegas.prentkovskis@vgtu.lt; ${ }^{5}$ kmdnor@management.utm.my; \\ 6abbas@management.utm.my (corresponding author)
}

Received 13 March 2017; accepted 08 May 2017

\begin{abstract}
This paper provides a conceptual architecture for a cloud based platform design, that implements continuously data storage and analysis services for large maritime ships, with the purpose to provide valuable insights for maritime transportation business. We do this by first identifying the need on the shipping market for such kind of systems and also the significance and impact of different factors related to shipping business processes. The architecture presented throughout this paper will be defined around some of the most currently used ICT technologies, like Amazon Cloud Services, Sql Server Databases, .NET Platform, Matlab 2016 or JavaScript visualization libraries. The proposed system makes possible for a maritime company to gain more knowledge for optimizing the efficiency of its operations, to increase its financial benefits and its competitive advantage. The platform architecture was designed to make possible the storage and manipulation of very large datasets, also allowing the possibility of using different data mining techniques for inferring knowledge or to validate already existent models. Ultimately, the developed methodology and the presented outcomes demonstrate a vast potential of creating better technological management systems for the shipping industry, starting from the challenges but also from the huge opportunities this sector can offer.
\end{abstract}

Keywords: transportation, business, cloud computing, competence, ship, maritime company, automatic ship performance analysis.

JEL Classifications: R40, R41, C8, L63, L86, L91.

\section{Introduction}

Over time, maritime industry has grown almost in a perfect correlation with the global world economy. As a consequence, maritime transportation business reacted both to global recession periods and flourishing ones. Today, we can notice that maritime sector 
includes a global community that uses high performance ships, advanced technological systems and skilled specialists (Paulauskas et al. 2014; Tzannatos et al. 2016; Lušić, Kos 2013; Stojaković, Twrdy 2016; Zhang et al. 2016; Tuljak-Suban 2017). It is well known that the water transportation is essential for many business around the world mainly because of the low costs when large ammounts of commodities are transported and the large number of interested parteners. As Mason and Nair (2013) stated, shipping can be considered the lifeblood of the global economy. More than $80 \%$ of the world goods are carried by ship. Agarwal and Ergun (2008) show that United States, the largest trading nation in the world, use sea cargo to move more than $90 \%$ of its export freight. There are three important elements that marine shipping is relying on: goods, ships and harbours. Because this research paper is focused on the ship operations, we considered that it is important to introduce some ship statistics (Statista GmbH 2016). In 2016, there were more than 50000 ships in the world. Bulk carriers were the most common type of ships in the global fleet, counting around 17000, which is more than $1 / 3$ of the total number. There is a specific tendency for many transportation companies to spend money on larger ships for increasing the capacities. Bulk carriers have a combined capacity of around 705 million tons deadweight in 2014, which is more than twice the volume of container ships combined capacity which was about 216 millions tons deadweight. As a consequence, there is an increasing growing pressure to reduce greenhouse emissions in the industry. The new builds of bulk carriers are forecast to produce $40 \%$ less carbon dioxide by 2040 . The second most common type of ship in the world is the cargo ship, which is a multi purpose vessel that can carry a wide range of products and goods. Also, in 2015 there were about 11000 cargo ships, which is around $20 \%$ of the global fleet. On the third and fourth place with 14 respectively $10 \%$ of the total number we find crude oil tankers and container ships. The number of crude oil tankers is about 7000, while cargo containers are around 5000.

Many global economic activities are in a continuously changing progress and as a consequence also the shipping industry is undergoing some structural changes. One of the most important changes can be found in the fact that the market, marketplaces and production are heading to a global state, and the production can be located everywhere. Fremont (2007) states that this new design of the world trade makes mandatory the need for a fully connected and highly integrated system. Also, Lorange and Fjeldstad (2010) emphasize that mega carriers with multi-ocean networks are now being the pattern. The shipping business environment is getting more instable, competition is increasing, profit margins are decreasing, expected service quality is increasing and demand is becoming more uncertain (Panayides, Wiedmer 2011; Panayides, Polyviou 2011; Robinson 2004; Tongzon et al. 2009; Bausys et al. 2015; Bagočius et al. 2014).

The shipping industry was seriously affected starting from 2013 because of the drop in oil prices, especially tanker trade. As presented in Clarksons PLC (2015) research, the price felt from 590 US dollars per tone in June 2014 to 318 US dollars per tone in December 2014, which means around 46\%. This had an indirect impact in many other areas of activity that were demanding maritime transport services. For example, there were changes in production costs, incoming and purchasing power of oil produceres, lower fuel and transport costs. 
Taken into consideration this economical context, we can assume that reporting and data analysis are key tools in understanding and improving complex operating environments, because the overall effects of any individual action can be very dificult to identify without a proper toolset. Identifying and continously improving the best practices within a maritime organization requires the capability to understand the operations on a level that can only be provided through data analisys and reporting.

The reporting activity can be performed in two ways. The first one is by using onboard systems that supports the implementation of best practices throughout the fleet by giving real time advices which will increase the performance of vessels. The second one is onshore reporting, where we want to create transparency throughout the operations, improve the understanding of the current status and differences between different vessels and to enable learning from the best performing vessels and implementing those best practices throughout the fleet. Usually, when is analysed a fleet performance in general, or a focused area of operations, it is possible to identify clear differences between vessels. Bringing the lowest performers to at least the level of average performers is often the fastest and most effective action.Taken into consideration this overall context, our study aims to propose an architectural solution for developing an analytical platform that would make possible to automate the process of obtaining valuable knowledge about a ship operation status, helping ship owners, charterers, shipbrokersto optimize the way ships are handled and utilized. As it will be presented in the study case, all these optimizations can bring benefits directly related to costs cutting and make the business more profitable.

This paper describe the architecture of a cloud based software platform that allow the automation of the following operations: continuously receiving ship automation data, parsing well-structured ship messages to get sensor data, storing historical ship data, parsing and storing information coming from different weather providers, continuously interpolating depth, sea currents and weather parameters related to wind, swell, waves for any ship location, use mathematical models to generate relevant knowledge based on available dataset, send important data to ships like course correction and weather information.

\section{Motivation}

As Keefe (2014) emphasized, the only thing harder than finding a needle in a haystack, is finding the sharpest points in a haystack full of needles, which is essentially the situation today on most vessels. Flooded with data coming from hundreds or thousands of ship sensors, it is up to domain specialists and maritime organizational management to reach that knowledge that will allow to cut costs and increase efficiency. All these sensors can collect and record hundreds of data points per second. Still, before using any modern technologies to dig into this resource, in search of knowledge, it must be prepared to build the necessary repositories to hold it. Even if this step is seen as an easy task, practice demonstrates that storing data is only a half of the problem, because afterwards will be permited the fast access. Usually, building systems for maritime 
industry management is a challenging task as this is one of the most conservative industries around. These organizations have been around for decades and since they are very cautious, it is hard for them to adopt the next big shinny technology.

In the present, the number of companies offering high-level technologies for optimizing ship operations is increasing. Based on their requirements, sensors are installed onboard in order to gather data. All types of ships data is gathered, depending of the ship type at least including trim, speed and propulsion machinery and navigational data, up to recording hundreds of different data sources for sophisticated cruise ships, which also have completely separate systems looking into the consumer behavior and onboard hotel and restaurant business operations. The technical data is typically first processed by computers onboard comparing performance with pre-stored statistical ship data. Some pre-processed data is sent ashore to the shipowners' office for further analysis. The trend is towards sophisticated systems where data processing is automated as far as possible.

Our approach, sustained and tested by the proposed platform architecture, presents also an economical knowledge creation scenario, based on one of the most widely used representation of the ship performance, respectively the speed-power curve.This representation displays the relation between the power consumption and speed through water, that may change in time. For example, when dealing with a brand new ship, its overall performance will be most probably at its best. Still, after some operation time, the hull and propeller condition may deteriorate because of biological fouling. This will lead to increasing power consumption required to move the ship at the certain speed, with direct consequences on operational fuel costs. In this case, the ship performance will decrease and the speed-power curve will move upward. The ship performance will again increase after some hull or propeller maintenance and the speed-power curve will move downward (Fig. 1).

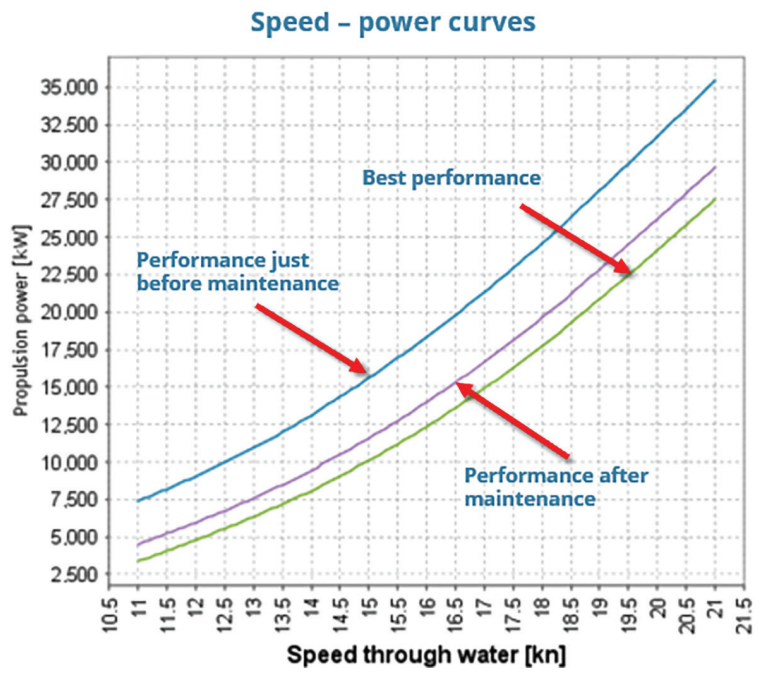

Fig. 1. Ship technical performance at different time moments 
Usually, the speed-power relation or the position of the curve is influenced by many factors. There are external factors, like weather and sea surface conditions, shallow water, biological fouling and internal factors, like ship loading conditions. All effects of different influential factors to the speed-power curve position can be modeled and separated with an aid of the statistical modeling. After the statistical model is created, the speed-power curve can be generated for any external and internal conditions. For example, it can be generated for Beaufort 0 weather (calm weather), zero meters swell, deep water and design draft, which will represent the ship performance for it can be called ideal conditions. Additionally, the speed-power relation can be generated for different moments in time which allows the comparison of the speed-power relation for certain time moments and estimate the change of the ship performance or impact of the hull and propeller fouling. For an easy understanding, it is possibile to calculate different performance indicators, like the propulsion power and speed losses and represent them graphically. The statistical model should make possible to calculate and demonstrate not only the effect of the decreased hull and propeller condition, but the effect of any variable which has an impact to the speed-power relationship. Starting from the current maritime industry context with its issues and needs, our challenge and motivation was to architect, build and test a platform thatcould offer competitive knowledge and advantage, providing enough flexibility to be further expanded according to new scenarios, that could help knowledge creation processes on the following aspects:

- What was the ship performance at the certain time moment?

- How much propulsion power or fuel is consumed to maintain the certain speed?

- How much the ship is consuming due to: decreased hull and propeller condition (biological fouling), different loading and floating conditions or different environmental conditions?

- Does the hull performance match the specification from the yard/owner?

- Is it the appropriate time for the hull maintenance?

- Where the ship energy is spent?

- How is the vessel operated?

- What is the engine specific fuel consumption in different engine load?

\section{Literature review}

Currently, available literature on methods and best practices to build large scalable systemson top new technologies like cloud, big data over satellite transmissions, in order to sustain knowledge creation in maritime sector, is quite sparse. We believe this applies not only forshipping, but also to the overall context where everyone, everything and everywhere will be connected in real time. Huge amounts of data are already available and we are just starting to learn how to harness this resource and concepts associated to it.

There are scholars that already presented results of using innovative technologies on different aspects of maritime industry. For example, Mihanović et al. (2016) defined several ways of using modern technologies in the maintenance of ships systems. Previously, Ristov et al. (2014) did several investigations on the implementation of cloud computing in ship industries. 
Perera and Mo (2016) emphasized the possibility and also the importance of collecting sensor data for future use. As they are noticing, modern vessels are mostly equipped with data acquisition systems that allows to collect large scale data sets that can be used to analyze and evaluate vessel performance levels under various weather conditions with different data analysis techniques.

Another scenario where we could see the benefits of a large maritime technological platform is presented by Lazakis et al. (2016) and it refers to monitoring ship systems condition for enhanced inspection and maintenance. In their example, they are using an enhanced central database that handles ship structures and machinery data. The collected data would be available to ship operators and utilized by the decision support system for ship structures and machinery for a continuous monitoring and risk analysis of ship operations. In his dissertation, Koga (2015) identifies some major challenges and solutions for utilizing big data in the maritime industry. A better understanding of ship energy use can prove to be very useful in the process of increasing ship energy efficiency. Baldi et al. (2014) based on ship operational data collected over a year identifies main producers, consumers and waste flows and provides a number of possible improvements guided by the improved knowledge of the ship's energy system.

Johnson and Styhre (2015) presented an interesting case about increasing ship energy efficiency through optimizing the time a ship spends in port. The authors used operational data from two ships in the company's fleet for one year showing that the ships spent more than $40 \%$ of their time in ports and that half of the time in port was not productive. As they stated the results show that even a conservative estimate of one to four hours of reduced time per port call would lead to a reduction in energy use of 2-8\%. If this kind of research would be sustained by data coming from hundreds, even thousands of ships, the results could be even more usefull from a business perspective. Regarding ship energy efficiency, Johnson and Andersson (2016) identified as a possible cause for shipping companies reluctancy towards energy efficiency programs the lack of scalable systems and information.

\section{Automatic ship performance analysis (A.S.P.A) platform}

From the information and communications technology perspective, last years brought good news to maritime industry as the current technological context allows these days the engineering of software platforms that could automatically handle the enormous volumes of data coming from myriads of ship sensors and on top of it to build the new generation of formal knowledge discovery algorithms, procedures and tools. As described by Miah et al. (2017), Lau et al. (2016) or Gandomi and Haider (2015), big data concepts started to be utilized in many industry fields. Still, due to the domain specific conservatism and not sufficient well tested tools, the maritime industry lacked this kind of approach. So, distributed data workflows can be coherently integrated into unified solutions that could bring well-founded findings about strategies applicable to shipping industry. A.S.P.A represents such a solution that was designed, based on a scalable model, to sustain the automation of ship data storage flow and of the paralel execution for ship efficiency analysis procedures. Figure 2 presents the internals of the A.S.P.A architecture. 


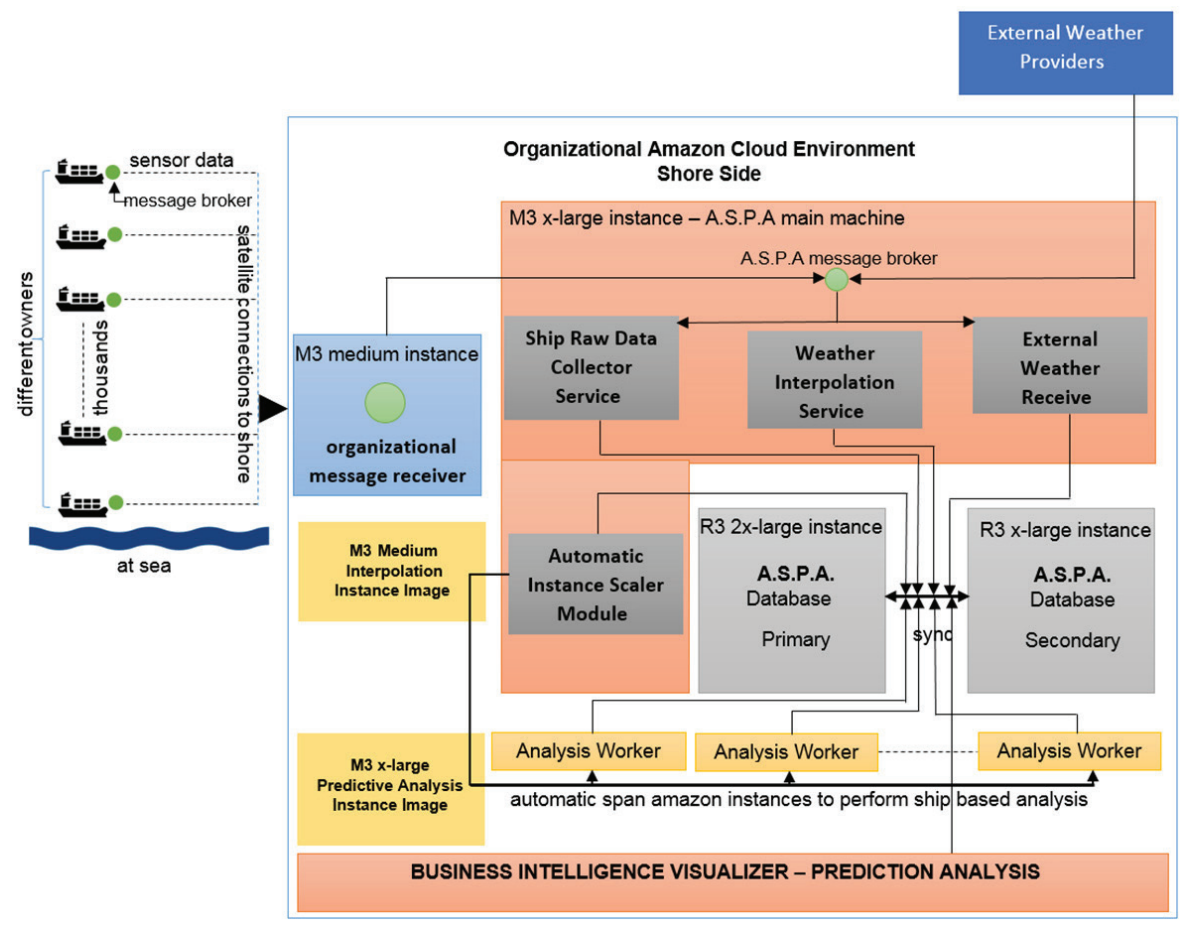

Fig. 2. A.S.P.A. architecture

According to Statista portal (Statista GmbH 2016), in 2016, more than 52000 large ships were sailing in the oceans. Each ship carries, possibly, hundreds of sensors that records measurements for each of the ship subsystems. In this huge amount of data, discoverable knowledge is hidden, but in order to reveal it, our machine learning algorithms needs warehouses with as much of this data. In this context, one of the first steps to be performed is putting in place a data sending mechanism from ship to shore. As it will be further discussed, message broker software sustained by satellite transmission could be used to send messages to shore. As many data formats are currently available, choosing one is a matter choice.

One important aspect of satellite communications is the price of the data transmission. Ships cannot send data continuously as it would be extremely expensive, so it would be much more effective to gather data on-board, aggregate it and send it, for example, several times per day. On the shore side, messages will be received using the same message broker tool and dispatched to the proper consumers. In our study case, one of the ship data consumers is the actual A.S.P.A platform so the platform will have its own broker that will receive ship data from the organizational message dispatcher. A.S.P.A platform was build entirely in the Amazon Cloud using. NET and $C$ sharp language as main programming tools, having as a data storage two Sql Server Databases. Platform architecture was designed around six main modules: ship data receiver, interpolator, scaler, weather data receiver, visualizer and prediction component. So, how it is actu- 
ally the data flowing in this architecture? Overall, there are two incoming data flows into the platform having as originators: ships and weather providers. After these types of data are stored, specific weather data will be interpolated for specific ship locations. After all necessary data is available, based on different Amazon Cloud images containing different machine learning algorithms modules, the system will scale up with new virtual machines, concurrently running, that will perform ship specific analysis of which results, representing insights on operational ship performance, will be also stored in the databases and used to create business intelligence reports for the organizational management.

\subsection{Ships at sea, sensor data and message brokers}

For many people, thinking about shipping would bring in their minds stormy seas, big and old shipping containers, dockyards and busy ports. Many would not even consider it a high tech industry, but the fact is that like many other industries at the moment, a technological and data revolution is taking place as we speak. The newest applied technologies could help shipping business in many ways. Let's take several examples:

- repair predictions;

- self piloting;

- cargo tracking;

- centralized knowledge;

- future design.

As we'll emphasize in this paper the business importance of weather forecasts, we believe that shippers are already benefiting from better forecasts that allows them to run more productively, such as choosing ideal routes, operate efficiently by choosing best-price fuels, or become more competitive. Also, as we'll point out, the Automatic Information System (A.I.S), a constellation of satellites that keep track of ship movements, could be fully used and integrated in shore side technological platforms giving shipping strategists a clearer understanding of how trade routes evolve over time.

Having large volumes of data available, many companies invests in the use of data science techniques and machine learning to more effectively predict customer demand on a molecular level - all the way down to a specific shipping container. Also, based on this large volume of data, mathematical equations and statistic techniques can be used to allow machines algorithms to predict the demand, which allows the shipping company to manage its operations accordingly. It is based on this context that we were motivated on researching a proper architecture and deploying process for a modern technological platform that would sustain maritime experts to optimize their business process, adding more value to their ongoing operations. The idea of our research was to identify good, if not best, practices, technologies and system architecture that would allow continuously storage of ship sensors data and scalable, customizable automation of the knowledge discovery process.

We had access to collect data from 160 ships, over a period of two years. The number of sensors per ship is quite specific, but as an average it would be more than one hundred, ship data being sent more than once per day. Speed through water, speed over ground, 
propulsion power, propulsion torque, true wind speed, specific fuel oil consumption, drafts are some example of parameters that are continusly measured and sent to shore. Bialystocki and Konovessis (2016) present some of the most important parameters to be used in ship efficiency prediction algorithms. In order to send and receive ship data ActiveMq message brokers were used, over satellite connections, to send and receive ship data. We defined three places where message brokers should be used: on ship, for sending messages to shore, at organization level,for dispatching any incoming message, according to its semantic and at platform level, used to receive specific data inside, A.S.P.A. Snyder et al. (2011) described practice aspects of ActiveMq software which represent an open source message broker, written in Java together with a full Java Message Service client. The communication in ActiveMq is managed with features such as computer clustering and ability to use any database as a Java Message Service persistence provider besides virtual memory, cache.

\subsection{Ship raw data collector service}

The raw data collector service represents A.S.P.A platform entrance for all ship operational related data. Its responsibility is to collect ship data and make it available for any other service that needs it. These days, there are two important methods on how we can gather data from ships:

- the ships are sending data messages to shore, containing sensor data;

- some operational data is accessed through different A.I.S providers.

Harati-Mokhtari et al. (2007) examine in his paper the usage of A.I.S on ship's bridge and its potential impact on the safety of marine navigation. As an example, in our study case, the collector service handled so far over 10 billion records, containing ship sensor measurement and weather data, for 160 ships, for around 100 sensors per ship, in a period of two years, having the database storage table reaching a size of $1 \mathrm{~TB}$ of data. Based on this data, currently it is possible to know for any of these ships, sensor parameter values for a specific time, during the last two years. In Figure 3, we present some data for a ship, dating more than a year ago. It would be also possible for maritime management to easily have such details for several ship/fleet. For example, loading 20 parameters, one year of data at five minutes interval, for six ships, it would take less than a minute.

\begin{tabular}{|l|l|l|l|l|}
\hline entry_time & Propulsion1Power & COG & SOG & LAT \\
\hline 2015-09-02 03:56:00.943 & 1344.4347826087 & 279.593380351063 & 6.35797740248965 & 0.54518201659751 \\
\hline 2015-09-02 04:01:00.943 & $1325.637362637 \ldots$ & 279.547802652557 & 6.2898834771784 & 0.545231788381743 \\
\hline $2015-09-02$ 04:06:00.943 & $1343.141304347 \ldots$ & 281.004132232263 & 6.27664715702477 & 0.545291446280991 \\
\hline $2015-09-02$ 04:11:00.943 & $1315.714285714 \ldots$ & 279.435660215808 & 6.24334843153524 & 0.545347713692947 \\
\hline $2015-09-02$ 04:16:00.943 & $1265.945652173 \ldots$ & 279.479338319376 & 6.14229596280989 & 0.545399012396694 \\
\hline $2015-09-0204: 21: 00.943$ & $1273.219780219 \ldots$ & 279.743806370395 & 6.070444 & 0.545450479338843 \\
\hline $2015-09-0204: 26: 00.943$ & $1308.758241758 \ldots$ & 280.03718839997 & 6.15016144214874 & 0.54550488016529 \\
\hline $2015-09-02$ 04:31:00.943 & $1275.413043478 \ldots$ & 280.835395629593 & 6.224777 & 0.545562242798354 \\
\hline $2015-09-0204: 36: 00.943$ & $1304.428571428 \ldots$ & 281 & 6.24624787603304 & 0.545621727272727 \\
\hline $2015-09-0204: 41: 00.943$ & $1278.369565217 \ldots$ & 280.800827950541 & 6.26298718672195 & 0.545679286307053 \\
\hline $2015-09-0204: 46: 00.943$ & $1280.153846153 \ldots$ & 280.930042239455 & 6.17904893827157 & 0.545738098765432 \\
\hline
\end{tabular}

Fig. 3. Random extraction of ship data parameters from a specific period 
Figure 4 presents the overall architecture of the ship raw data collector, displaying the interaction between A.S.P.A internal components and the external sources of data.

As presented in Figure 4, ship raw data collector service is mainly responsible forhandling and parsing xml data files, delivered from organizational message broker after they were received from ships, via satellite connections. For the solution presented in this paper, A.I.S. data was not taken into consideration, even if it represents, if available, a valuable asset for a maritime corporation. Still, due to its importance, it will be addresed again in the last chapter of the paper.

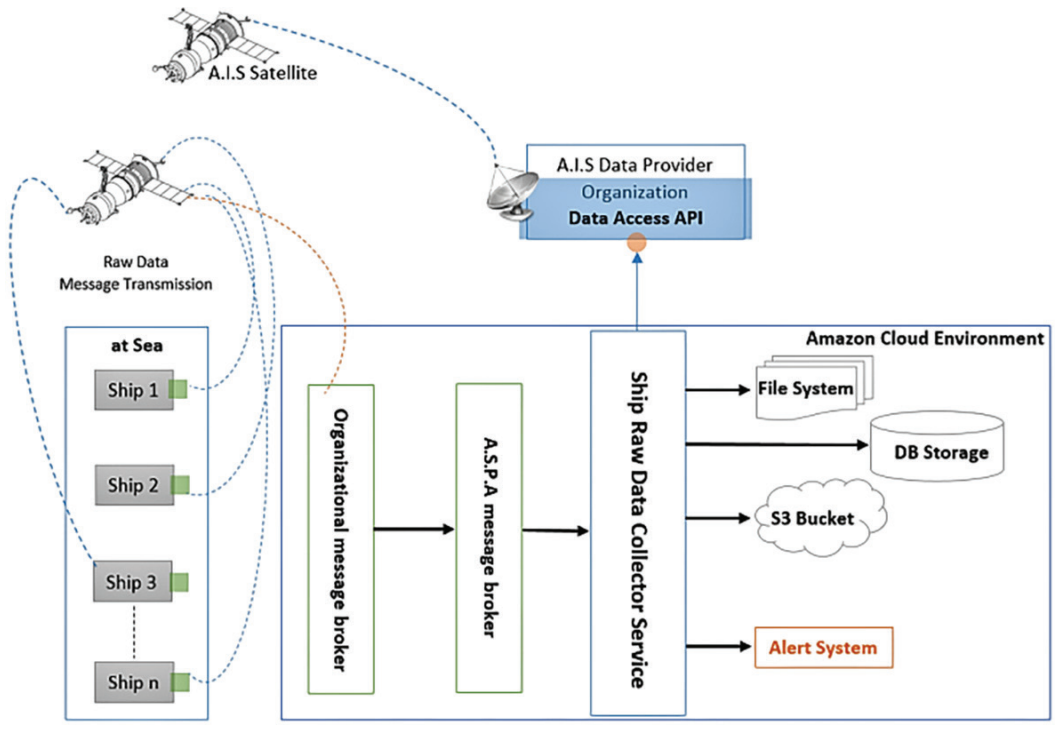

Fig. 4. Architecture of the ship raw data collector

The architecture presented in Figure 4 implements the following functionality:

- read the data messages;

- parse message content;

- dump data to A.S.P.A database;

- saves incoming messages to file system or Amazon Cloud buckets - for archival and safety issues;

- send mail alerts for critical situations like - no data is coming from ship, corrupted messages that cannot be parsed, connectivity issues with storage mediums;

- identifies the missing parameters names from the incoming messages and automatically updates A.S.P.A data structure, for the situation when ships are sending data for sensors that are not mapped in the database.

\subsection{External weather providers}

Weather data is one of the most important assets for any proper investigation related to maritime operations. Actually, we believe that any business intelligence solution for this sector should handle this type of data. This believe is based on the fact that weather 
and sea conditions forecasts were included in many research studies and experiments related to maritime industry. By studying specialized literature, we identified the following scenarios where weather forecasts are mostly used:

- determining how ship navigation is affected by extreme weather conditions (Xia et al. 2006);

- identifying algorithms and models for the prediction of ship speed and power for different weather states (Chen et al. 2013; Soda et al. 2012);

- determining fuel savings algorithms (Hellström 2003);

- researching new architectural ship designs, for example flettner rotors design (Traut et al. 2014);

- determining different ship routes based on weather and sea currents forecasts (Padhy et al. 2008; Tsujimoto, Tanizawa 2006; Panigrahi et al. 2012; Zhang, Huang 2007; Cai et al. 2014);

- analysing characteristics of propulsion performance under various weather and sea conditions (Sasaki et al. 2010; Yokoi et al. 2010; Tsujimoto, Tanizawa 2006; Kayano et al. 2013).

Hellström (2003) emphasized that fuel costs are the second largest item (after salaries) on a big vessel's budget. For example, for a large ferry, fuel consumption ranges between 1000 and 5000 litres per hour. It is easy to prove (based on actual data received from hundreds of ships) that the annual fuel budget for a large ship that is running more than 20 hours per day is in the order of millions of dollars. Even small reductions of a few percent off the fuel consumption means considerable annual savings. Usually, researchers most optimistic fuel savings would be around $5-10 \%$, corresponding to at least 1 cubic meter of heavy fuel oil per day. According to Hellström (2003), these kind of savings will be achieved by optimizing control at three levels:

- pitch optimization - the pitch angle of the blades on a controllable propeller acts as a kind of gear box, and affects the ship's speed together with the main engine's revolutions $[\mathrm{rpm}]$;

- dynamic control of speed to avoid sudden peaks in fuel consumption caused by low water depth, or unanticipated changes of the weather conditions;

- route planning - the fuel consumption for a ship depends not only on speed, but also on water depth and weather conditions.

The optimal speed distribution along the route can be computed in advance, if a weather forecast is available.

Flettner rotors ship design came as consequence after the Energy Efficiency Design Index (EEDI) was made mandatory for all new built ships, together with Ship Energy Efficiency Management Plan (SEEMP) for all existing ships, under the amendments made to MARPOL Annex VI (Traut et al. 2014). The result was that contemporary shipping started to undertake a big challenge: reduce fuel consumption and the emission of $\mathrm{CO}_{2}$ to meet the prescribed MARPOL targets. Wind propulsion was an interesting topic for a reduce emission strategy. The potential benefits were quite appealing: by reducing fuel consumption of a ship there will an increase in profit margins, a reduced freight rate and overall a reduction in greenhouse gas emissions. For this kind of ships, the importance 
of wind forecasts is quite obvious. Basically, part of their overall performance is based on wind speed and direction.

According to Cai et al. (2014), we should consider as important environmental factors for ship routing those elements such as the atmosphere and ocean which may produce a change in the status of a ship transit. Therefore, for ship routing, we can consider as important factors: waves, wind, ice, fogs and ocean currents (both speed and direction). It is difficult to determine the effect of wind speed/direction on ship performance. Usually, in slow winds, ship will lose speed in headwinds and will gain speed in the case of following winds. If wind speed is high, the speed will be reduced in both cases due to the increased wave actions and steering corrections. Cai et al. (2014) show that the major factor that will affect ship performance is the wave height. This situation is a consequence of the fact that the waves will reduce propeller thrust and increase drag from steering. Therefore, in the context of heavy winds and waves, it would prove very useful, for ship handling and overall comfort, to be able to predict the ship performance. From routing perspective, ocean currents do not represent a major problem, but still, they can play a determined role on route selection, especially when departure and destination ports are on low latitudes. Ocean currents are more accurate to forecast, as they are not changing very fast, but extreme weather conditions, like hurricanes or global phenomenon, can change currents speed and direction for several days.

As stated by Kayano et al. (2013), weather routing represents one of the technologies used for ship energy saving and it is widely adopted by oceangoing merchant ships. According to Yokoi et al. (2010), the weather forecast technology has been improved year by year and an easier method to obtain the worldwide accurate weather forecast data has been proposed. Still, the effectiveness of the weather routing depends on the accuracy of weather forecast data and the ship's propulsion performance prediction. As Sasaki et al. (2010) and Tsujimoto and Tanizawa (2006) mentioned, the propulsion performance in the actual sea is usually predicted using the self propulsion factors obtained by model tests. Therefore, it would be necessary to understand the propulsion performance characteristics in the actual sea conditions for the improvement of propulsion performance prediction. Kayano et al. (2013) emphasize that usually, in the actual sea, ship's speed is low when compared to the speed measured in still water trials. In this context, for improving the accuracy of a propulsion performance prediction model, it is important not only to understand the effect of external factors like wind and wave on the propulsion performance but to base our research on very accurate weather forecasts. Borkowski et al. (2012) also show that in general, the performance of a ship in service is different from that obtained on shipyard sea trial. Apart from any differences due to loading conditions, and for which due correction should be made, these differences arise principally from the weather, fouling and surface deterioration of the hull and propeller and in this case, the weather effects need to be taken into account if a realistic evaluation is to be made. During the past decade, we witnessed more extreme weather, both in land and at sea. Typhoons are bigger and stronger, which leads to more high waves in the ocean. 
As a consequence, vessel navigation will involve higher risks. Besides weather routing for oceangoing ships (Motte 1972; Bowditch 2015) and the Ensemble Prediction System (EPS) run at European Center for Medium range Weather Forecasting (ECMWF), many ships navigating in coastal areas will need exact weather and ocean forecasts because of topography complexity and higher ship density (Hoffschildt et al. 1999). Chen et al. (2013) presented this case starting from a busy shipping area like Osaka Bay in Japan, which is often attacked by strong typhoons coming from different directions. Chen et al. (2013) emphasized that the need for high-resolution information on wind, waves, and currents has been brought to the attention of scientists and engineers.

Shiotani (2002) studied the influence of tidal current on a sailing ship, making the initial step of numerical ship navigation. Another several numerical navigation experiments in the Japan coastal area were also carried out (Xia et al. 2005, 2006), verifying the possibility to estimate ship position, however, the high-resolution weather and ocean data was not utilized to improve the accuracy of ship simulation. Shiotani (2002) analysed the combined effects of tidal current, wave and wind on a ship specifically for Bay of Japan, indicating a good agreement between simulation and observation of the weather and ocean data. Soda et al. (2012) also studied the influence of weather and ocean on a sailing ship in coastal area, however, their simulation was conducted using only a small vessel "Fukae Maru" but without proper data verifying data.

\subsection{Weather receive service}

For maritime industry, accurate weather data plays a very important role in many scenarios. From the business operational point of view, energy efficiency analytics forecasts, speed profiling, route optimization, forecasting maintenance periods, navigation in heavy weather conditions are based on weather data. In particular, as trying to sustain knowledge creation, we believe that any technique used in this sense, for example machine learning, data mining or statistical modelling, would not prove useful and the results would be hard to validate in the absence of weather data. Based on this assumption, A.S.P.A platform integrates a scalable weather receive and storage mechanism that allows large volumes of weather data to be received and stored for subsequently usage.

Over a period of more than two years, we continuously received weather messages from several providers, accumulating over 22000 files containing world wide weather coverage data for the entire period. For optimization purposes, we used for file formats one of the standards used by many meteorology organizations, respectively GRIB (GRIdded Binary or General Regularly distributed Information in Binary form). Sahasrabuddhe and Jamsandekar (2015) describe GRIB as being a concise data format commonly used in meteorology to store historical and forecast weather data. It was standardized by the World Meteorological Organization's (WMO) Commission for Basic Systems, known under number GRIB FM 92-IX, described in WMO Manual on Codes No 306 (WMO 1995). Three versions of GRIB were developed, from which he first edition that is used operationally worldwide by most meteorological centers. Still, a newer generation has been introduced, known as GRIB second edition, and data is slowly changing over to this format. From a structural point of view, GRIB files are a collection of self-contained 
records of $2 \mathrm{D}$ data, and the individual records stand alone as meaningful data, with no references to other records or to an overall schema. Moving to our implementation of a weather handler service, Figure 5 presents it from a functional point of view.

As presented in Figures 5 and 6, the weather service will continuously listen A.S.P.A message broker for new content of type weather and when these are found they will be passed to Process Incoming Weather Message function. Process Incoming Weather Message function performs several tasks. First step will be to store metadata about each weather file that it is handled. Metadata represents stored information on the date the message was received, the keyname used for cloud storage, weather provider identification, the invalid value that describes corrupted data and coordinates that define what world area it covers.

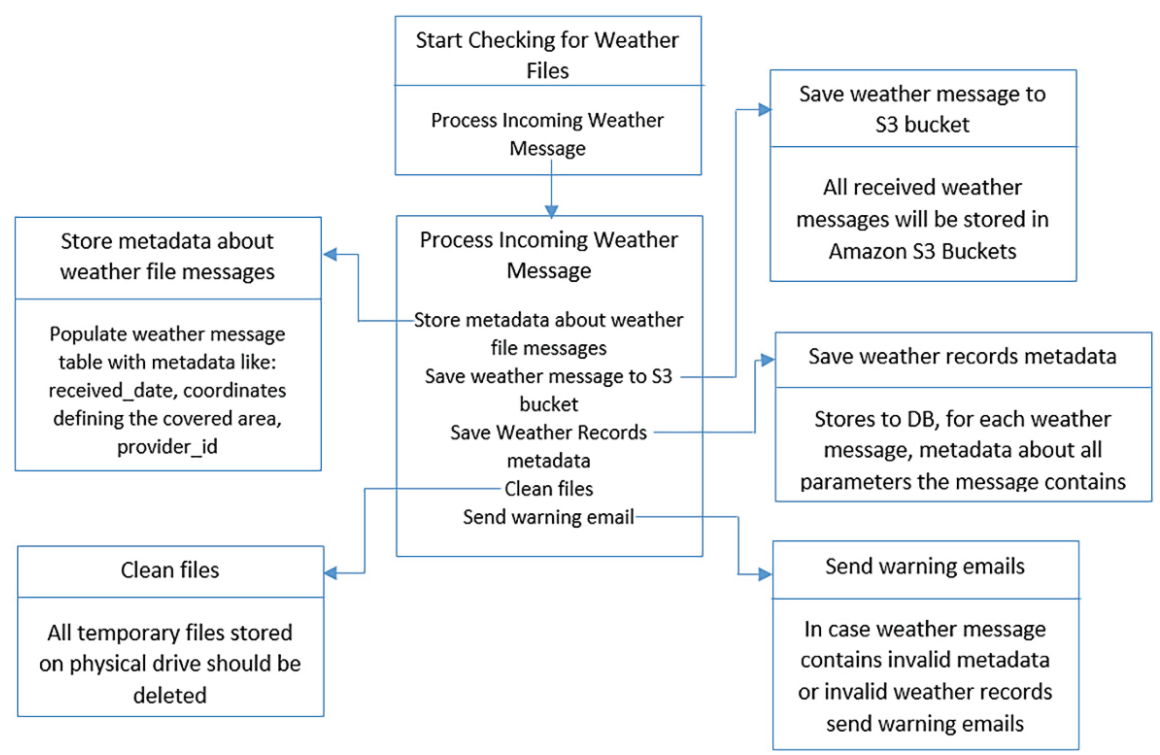

Fig. 5. Functional architecture of external weather receiver service

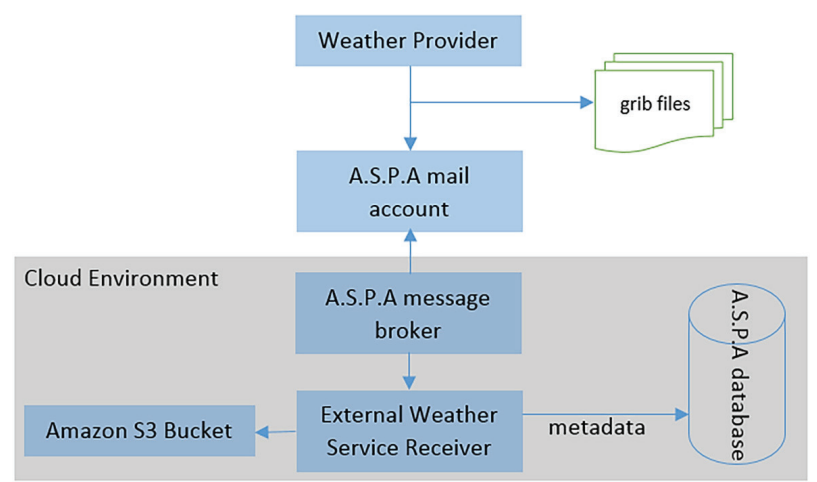

Fig. 6. Import weather service overall architecture 
Storing all content of weather messages in the database it would mean a huge waste of resources. Only one grib file can contain over $10^{6}$ records, so just for one provider, over a year it would mean $365 \cdot 10^{6}$ records. One aspect of knowledge creation processes based on predictive techniques is that they are requiring as much data as possible. One year of data it is ok, but five years would be better. One provider, with one set of parameters is fine, but five would be much better.

Taken this into consideration, plus the fact that much of the weather will remain unused, because of the ship route dynamic, plus low costs on cloud storage, we moved the repository for these files to cloud, sustaining this approach with an algorithm that will download, for usage, only the files that are needed. The next step after storing weather message in $S 3$ cloud buckets is to store metadata on the records contained in the weather message. This will allow for each file to easily identify what parameters it contains and for what time the data was forecasted. In the end, we clean all temporary files stored during processing and send warnings in case message files contains invalid coordinates or weather message records contains invalid forecasted dates. It is necessary to be warned on invalid dates or coordinates because, otherwise, interpolation subsystem could consider that there is proper weather data that can be used while, in fact, there isn't. Starting from the above discussion, Figure 6 presents the overall weather service architecture.

Summarizing, the weather providers sends the messages into A.S.P.A mail account where A.S.P.A based on its internal rules will send appropriate content to external weather service receiver that will perform two important task: first it will store/archive the files in a cloud bucket and than it will store, in A.S.P.A database, metadata about weather files and the records that it contains (which are the actual parameters), which can be used by any external functionality that requires weather data, even for a longer period of time.

\subsection{Weather interpolation service}

As weather data files, containing parameters data, were built based on a predefined resolution for storing actual weather values (Fig. 7), one important characteristic of our platform is the ability to correctly approximate sea conditions for specific coordinates in time (according to ship position and time of the measurement). Coordinatesresolution can vary between providers or between parameters. As an example, for a provider, sea currents parameters are defined using a 0.25 resolution grid, while wind related parameters are using a 0.5 resolution. For other providers/parameters the grid resolution can vary even more: $0.1,0.08,0.02,1.25,0.001$, etc. In this context, our interpolation functionality was developed in such a way to provide, as much possible, accurate weather data values for any reported ship position during the voyage of a ship.

At the moment, for better estimations and validation, weather data coming from five different providers it is used. They are sending data covering all important aspects related to sea conditions, like: sea currents speed and direction, tidal currents speed and direction, air pressure, wave heights, wave direction, swell heights, water temperature, water salinity, wind speed, wind direction, ice concentration, salinity, etc. Interpolating 
weather parameters requires two conditions. First of the conditions is that available weather files should contain data for the necessary dates, determined from the timestamps when ship sailed over certain coordinate.

Also, it is mandatory for the ships to send both latitude and longitude for their position and the reference time of the measurement (Fig. 8).

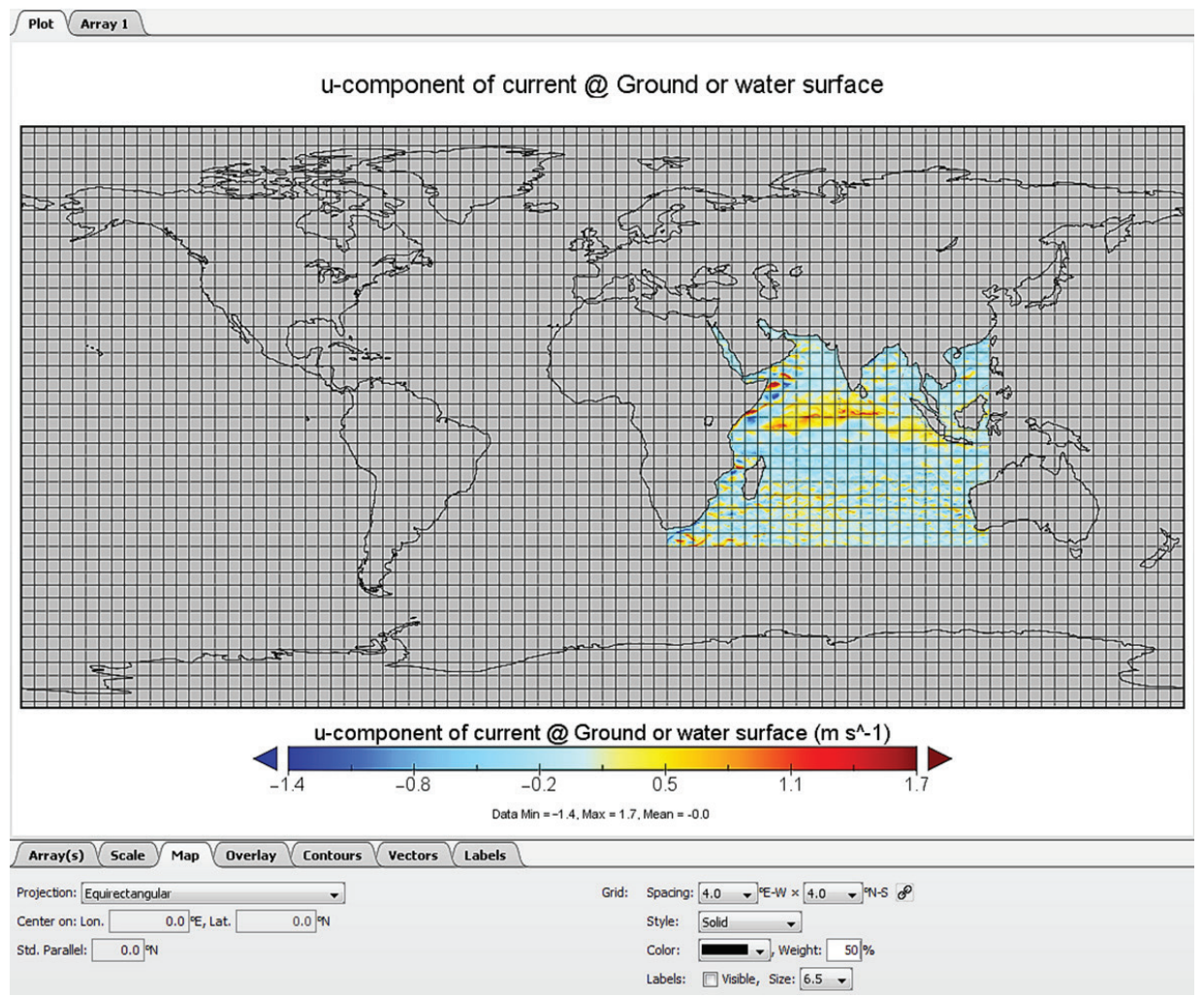

Fig. 7. Parameter data on a 4-degree step map for Indian Ocean, from a GRIB file

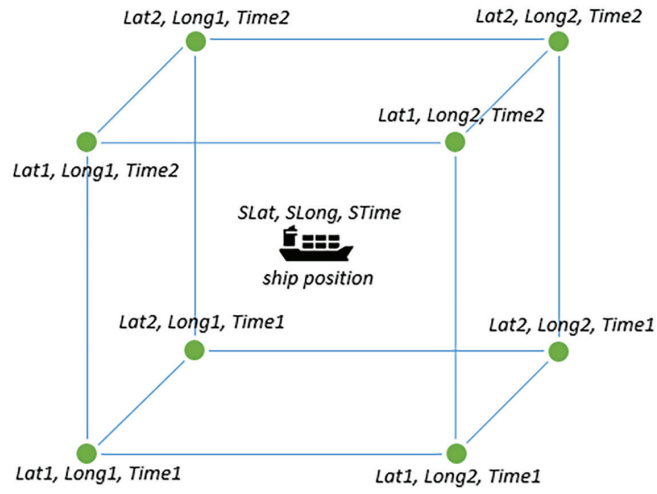

Fig. 8. Ship position from a trilinear interpolation perspective 
If we are to emphasize some important characteristics for the interpolation service, these would be:

- interpolation must be a continous proces, that is when new ship records are stored, a new set of interpolated weather values should be calculated and stored;

- all coordinates sent by ship can be interpolated by weather data sent by external providers;

- the service should cover the case when, for some coordinates, there is no weather data available, taking as example the situation when weather files containing necessary data were received after the arrival of a ship message; in this case, the service; will have to interpolate the missing coordinates as soon the required weather files are sent by providers;

- interpolation procedure could be also called on user request, allowing user to choose every interpolation detail, like: used database, time periods, necessary ships, specific parameters.

In our analysis, the interpolation algorithm used either trilinear or bilinear approach. Trilinear interpolation is a method of multivariate interpolation on a 3-dimensional regular grid. It approximates the value of an intermediate point $(x, y, z)$ within the local axial rectangular prismlinearly, using data on the lattice points. For an arbitrary, unstructured mesh, as used in finite element analysis, other methods of interpolation must be used; if all the mesh elements are tetrahedra, then barycentric coordinates provide a straightforward procedure. Trilinear interpolation is frequently used in numerical analysis, data analysis, and computer graphics. In practice, a trilinear interpolation is identical to three successive linear interpolations, or two bilinear interpolations combined with a linear interpolation. In our case, the formulas used for the trilinear interpolation, which actually is used for calculating weather and sea currents parameter values are presented below. The bilinear interpolation, used mainly to calculate depth values, for specific ship coordinates, follows the same principle, with the only difference that there is no time coordinate involved.

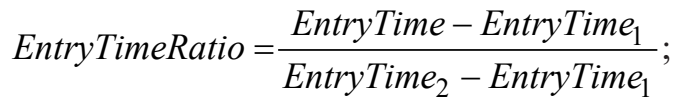

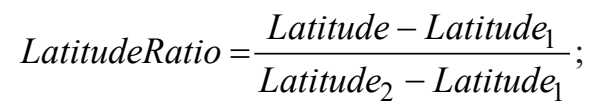

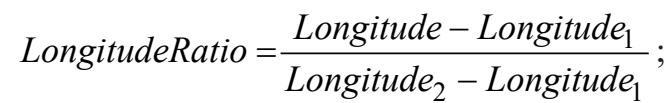

$$
\begin{aligned}
& \text { Waves } \left._{i j k}=\text { Waves }_{\left(\text {EntryTime }_{i}\right.} \text { Latitude }_{j}, \text { Longitude }_{k}\right) \text {; } \\
& \text { Waves }(\text { EntryTime, Latitude, Longitude })=(1-\text { EntryTimeRatio }) \times
\end{aligned}
$$

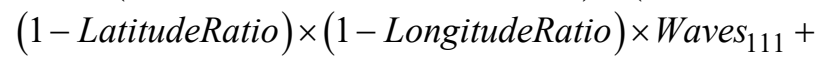

$$
\begin{aligned}
& (1-\text { EntryTimeRatio }) \times(1-\text { LatitudeRatio }) \times
\end{aligned}
$$

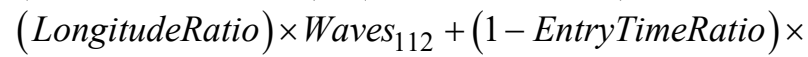

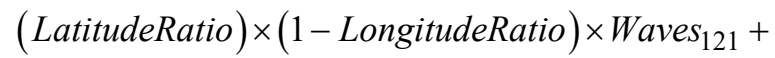

$$
\begin{aligned}
& (\text { EntryTimeRatio }) \times(1-\text { LatitudeRatio }) \times(1-\text { LongitudeRatio }) \times
\end{aligned}
$$




$$
\begin{aligned}
& \text { Waves }_{211}+(1-\text { EntryTimeRatio } \times(\text { LatitudeRatio }) \times
\end{aligned}
$$

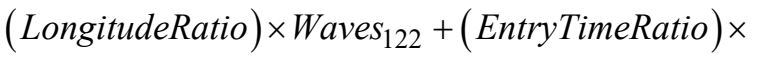

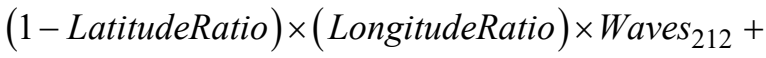

$$
\begin{aligned}
& (\text { EntryTimeRatio }) \times(\text { LatitudeRatio }) \times(1-\text { LongitudeRatio }) \times \\
& \text { Waves }_{221}+(\text { EntryTimeRatio }) \times(\text { LatitudeRatio }) \times \\
& (\text { LongitudeRatio }) \times \text { Waves }_{222} \text {. }
\end{aligned}
$$

\subsection{Automatic instance scaler module}

The A.S.P.A. scaler module handles the dynamics of the platform computational power. It is responsible for spanning Amazon instance machines that are used in two scenarios: running predictive statistical analysis automatically, respectively on demand, for any needed ship and running interpolation procedures - when more intensive scenarios are especially user requested. Figure 9 presents an overview of the service both from an architectural and a functional point of view.

The scaler service is continuously scanning the database in order to identify ship analysis that must be performed. Several conditions should be met in order for an analysis to be executed: it must have sufficient historical and current data available, it should not be executed too often as the results will remain unchanged and financial resources will be useless spent, it must not be on purpose marked as not to be executed. The results of any performed analysis, which contains formalized potential knowledge, are stored in the database in the appropriate tables and offered to end user. Because running a predictive analysis would require more than an hour for one ship, it would not be at all scalable and efficient to use only one or two machines to execute them sequentially. Instead we implemented a dynamic approach where, depending on how many analysis we have to execute, the scaler will span from an amazon image as many working virtual machines (workers) needed. For this type of computational tasks, Amazon Cloud M3

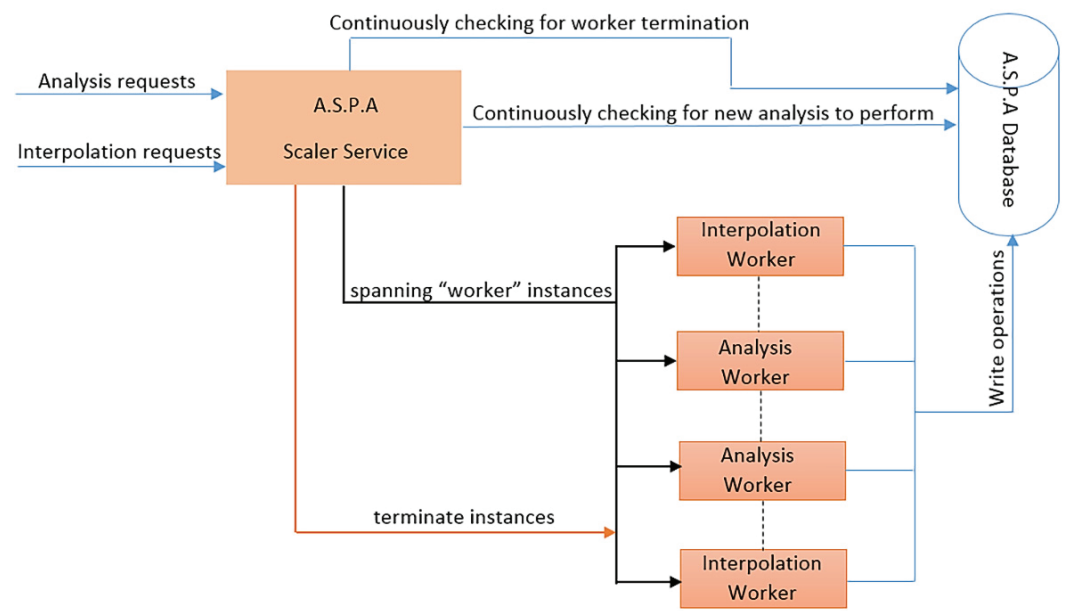

Fig. 9. A.S.P.A scaler module 
family group, version m3.medium machines are used. These machines provides a good balance of compute, memory, and network resources, being a good choice for many applications. They have high frequency Intel Xeon E5-2670 v2 (Ivy Bridge) virtual processors and solid state drives for better I/O performance. As the output is not stored locally, we were not very concerned about their storage size.

Another important task of scaler service, besides creating operational instances, is to properly terminate the launched instances, when they finish the assigned jobs. This procedure involves also a continous scanning of the A.S.P.A. database in order to determine which analysis has finished succesfully or not. When such case is found, the assigned working instance will be terminated immediately.

\subsection{A.S.P.A database server and database structure}

All services and modules in A.S.P.A platform are using for storage and synchronization purposes a Sql Server Database, deployed on two Amazon Cloud instances of type r3.xlarge and r3.2xlarge with storage size increased to accommodate their sizes. $R 3$ instances are optimized for memory-intensive applications, they feature High Frequency Intel Xeon E5-2670 v2 (Ivy Bridge) Processors, SSD storage, 30 and 61 gigabytes of RAM, 4 and 8 processors and are recommended for high performance databases, distributed memory caches, in-memory analytics. The database structure for the presented platform was created to sustain four general contexts: weather data, ship data, analysis metadata and predictive/statistical analysis results. Figure 10 presents the table architecture of the database that is currently used in A.S.P.A. development process.

Ship table contains mainly design related data for the ships. As example for this kind of data, we could have displacement, length, width, deadweight, maximum power, service speed, gross tonnage, etc. From the storage perspective, ship table it is not a large table, being capable, if necessary, to store without any constraints all ships in the world. Having all ships available, with their details, on A.S.P.A platform, could be easily done

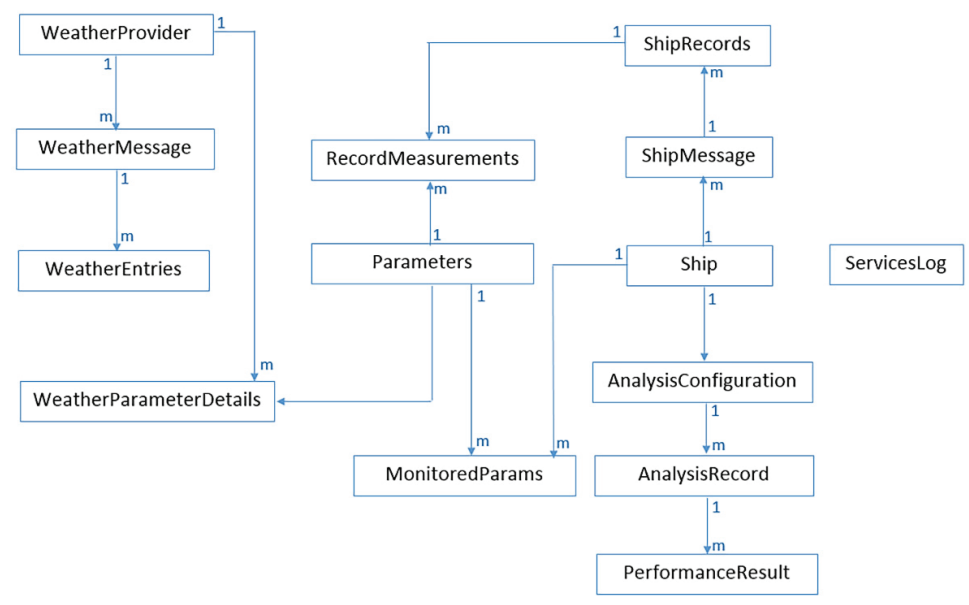

Fig. 10. A.S.P.A database main tables 
with the help of some A.I.S. Api calls and it could prove useful for any organization that would like to invest in competition analysis analytics. All ships, in our context, are sending XML data messages to shore, ShipMessage table being responsible to store information about the name of the file, as it would be named for cloud storage, respectively date and time when file arrived on shore. Each ship message contains a list of record (hence 1:m relationship) which are stored in the ShipRecords table together with the messageid, base time of each record and a flag column that will be set by an internal module in case weather data is available for that parameter.

Each ship can send daily from one message to 50 messages, containing different number of records, depending on the ship communication system characteristics. For every ship record there are usually more than 100 measurements that are stored in the RecordMeasurements table. Therefore, this table should contain and make available to different modules all ship sensor data across time. It is by far the most dynamic and biggest table of our platform, its increasing rate being approximately $X$ records/ship. From columns perspective, it should contain a parameter and a record identifier, respectively a column containing the actual measured or interpolated value. Parameters is almost a static table, containing all measured parameters (around 2500), new records being added automatically in case new sensors deployed on board some ships are starting to send data. MonitoredParameters table stores a subset of parameters, appreciated as the most important by the domain experts, in order for a close monitoring on the data that the ships are sending. For example, latitude and longitude can be considered as highly important parameters because in case they are missing or their values are corrupted, the entire record becomes useless. Weather provider contains all possible providers for weather messages, each of them being able to send multiple messages containg weather forecasts, for each of these files their metadata being stored in WeatherMessage table.

Any weather message contains a specific number of weather entries, which are actually representing the weather parameters each provider is sending. Storing all values for weather parameter values inside the database would be a waste of resources so only the required metadata is retained, file being $S 3$ archived, in order to be subsequently used when its actual value will be needed. Every ship can have one or more specific configuration that will be used by the statistical analysis, stored in AnalysisConfiguration table, and for any configuration one or more analysis could be run, AnalysisRecord representing the table that will store information on each analysis, like the date/time it started, outcome, date/time it ended, id of the cloud machine that actually performed it. For any analysis there will be more results, as specific, formal, numerical values, that will be stored in PerformanceResult table. In the end, the ServicesLog table will be used by any running procedure/module that will need to log parts of its execution.

\subsection{Business intelligence visualizer and knowledge discovery}

Based on automatically collected data, the instance "workers" in the cloud will continuously run new analysis whenever analysis conditions are fulfiled. Based on the stored result, business intelligence reports, with valuable business insights can be generated. For example, one performance analysis was performed for a specific ship for a period between 29 October 2014 and 16 June 2016. This analysis was one of the many per- 
formed for testing A.S.P.A scalability and ease of usage to benchmark ship's performance and, for this particular case, the difference after repainting the hull during the dry-docking with a new type of low friction paint. Measurements started to be sent from October 2014 and during the measurement period, the ship operated all over the world. The sailing routes are presented in the Figure 11.

A.S.P.A platform also allows to visualize route segments, based on input dates, having also speed profiles associated (Fig. 12).

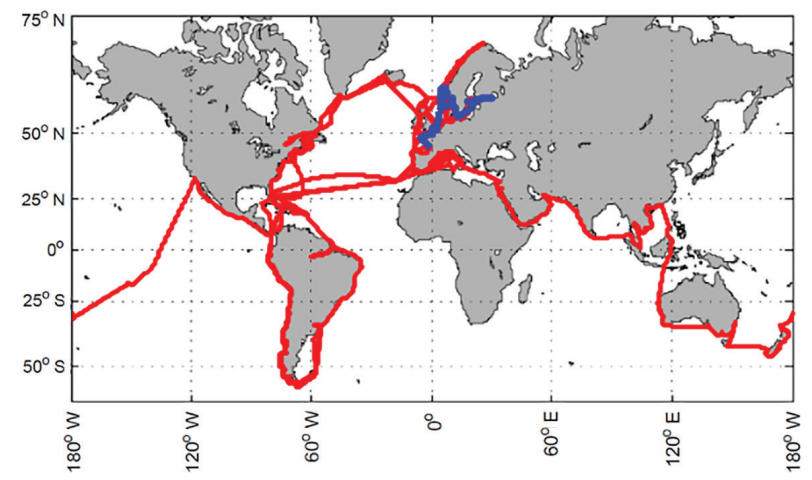

Fig. 11. Sailing route (16 May 2015 - 16 June 2015 plotted in blue)

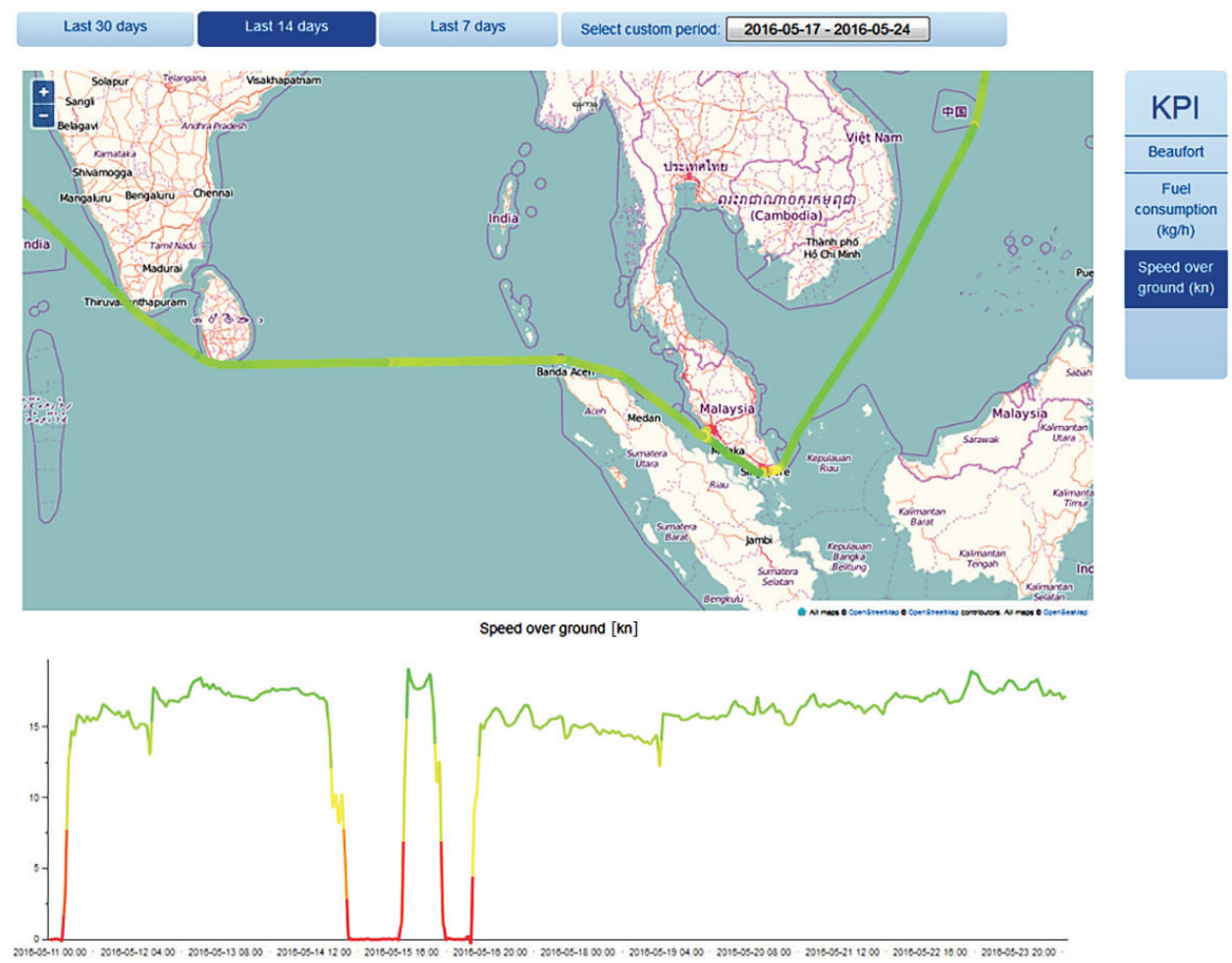

Fig. 12. Sailing route for a specific period with speed over ground profile 
For any performance analysis A.S.P.A platform has to execute, the following recorded parameters/units are mandatory:

- GPS position [lat/lon];

- speed through water $[\mathrm{m} / \mathrm{s}],[\mathrm{kn}]$;

- speed over ground, $[\mathrm{m} / \mathrm{s}],[\mathrm{kn}]$;

- course over ground $\left[{ }^{\circ}\right]$;

- heading $\left[^{\circ}\right]$;

- shaft RPM's [rpm];

- true wind speed $[\mathrm{m} / \mathrm{s}],[\mathrm{kn}]$;

- true wind direction $\left[^{\circ}\right]$;

- current (drift) speed [m/s], [kn];

- current (drift) direction $\left[^{\circ}\right]$;

- propulsion power [kW];

- engine power/load (for each) [kW];

- drafts [m];

- fuel flow $[1 / \mathrm{h}]$;

- water depth $[\mathrm{m}]$;

- air temperature $\left[{ }^{\circ} \mathrm{C}\right]$;

- stabilizer fins [in/out].

The values were recorded with 5 min interval using running average. Speed through water signal is very essential for the performance analysis. Speed log signal usually has some error which can be corrected by analyzing the measurements against speed over ground and temperature. Following corrective actions were made for the measurements by the speed log. It was noted that Longitudinal Water Speed (LWS) and Transversal Water Speed (TWS) measurements correlate before dry-docking (Fig. 13). After that, TWS is close to zero on average as it should be. It is assumed that still Speed Through the Water (STW) calculated from LWS and TWS is accurate enough and can be used in the analysis.

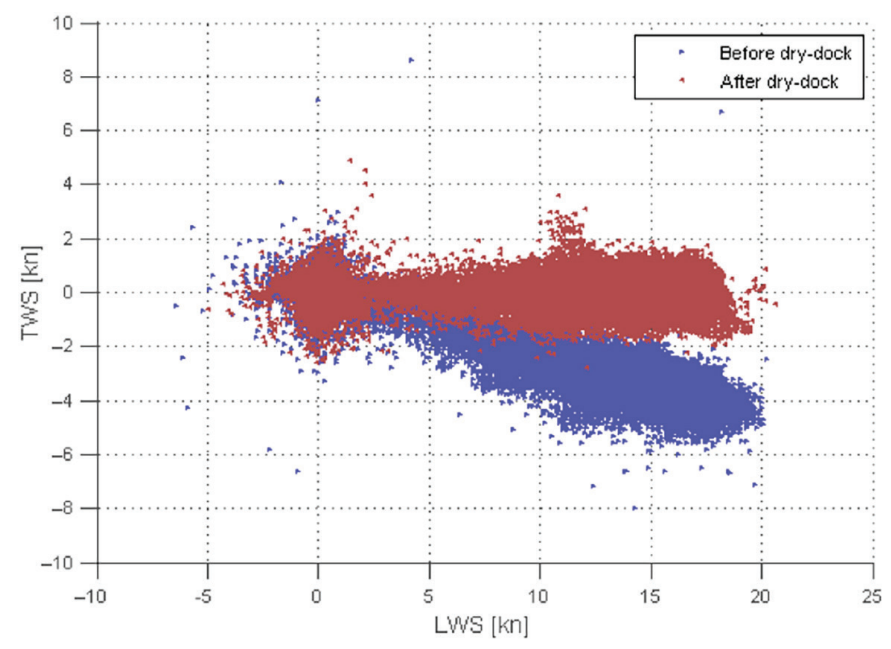

Fig. 13. LWS vs. TWS scatter plot 
The measurement error of speed through water is clearly dependent on water temperature, because the ratio of STW to Speed Over the Ground (SOG) correlates with air temperature (Fig. 14), which represents water temperature as it was not available. Measured STW values are corrected according to the fitted line (i.e., each measured STW is scaled by the value of the fitted line at the temperature of the measurement time).

During the analysis stage, the propulsion power values were filtered, normalized and then compared to the sea trial curve. Data points are filtered to find the most suitable of them for the analysis, that is, the ship is not speeding up, decelerating or steering. Also data points from rough weather conditions and from shallow water are filtered out. The following filtering conditions are used:

- differences in heading to the preceding and the following data points are less than $0.5^{\circ}$;

- differences in speed over ground to the preceding and the following data points are less than $0.3 \mathrm{kn}$;

- speed through water is between $11 \mathrm{kn}$ and $19 \mathrm{kn}$;

- water depth is more than $15 \mathrm{~m}$ according to both echo sounder and ocean depth database;

- relative wind speed is less than $25 \mathrm{~m} / \mathrm{s}$;

- significant wave height is less than $1.5 \mathrm{~m}$.

A statistical regression model is fitted to the set of filtered data. The effects of wind and waves are estimated and their contribution to the measured shaft power is removed to produce normalized propulsion power values. Figure 15 illustrates the estimated effect of wind on the power consumption at $16 \mathrm{kn}$ speed. Headwind and crosswind are relative to the ship, i.e., they are calculated from the speed over ground and the true wind measured onboard by the ship's anemometer. It is assumed that the power increase due to wind is proportional to the speed through water. The contributions of wind are calculated accordingly for each filtered data point and they are subtracted from the measured propulsion power values.

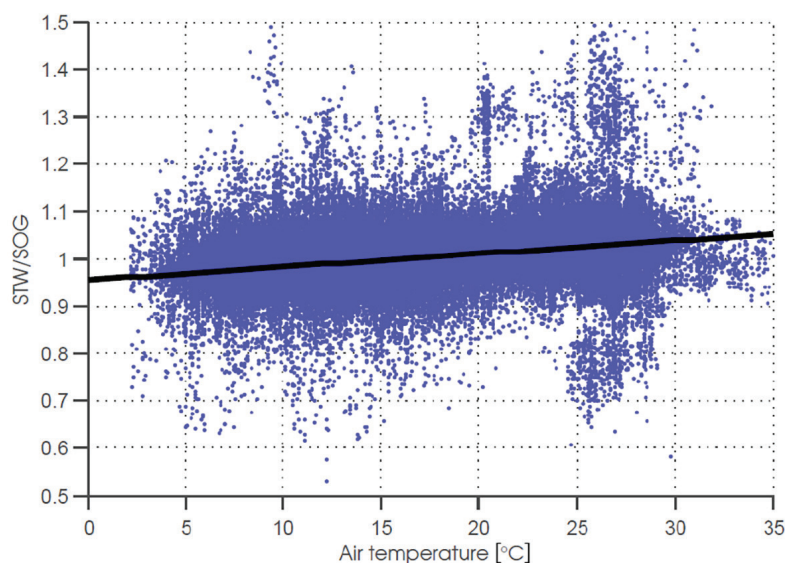

Fig. 14. Dependence of STW/SOG on air temperature 


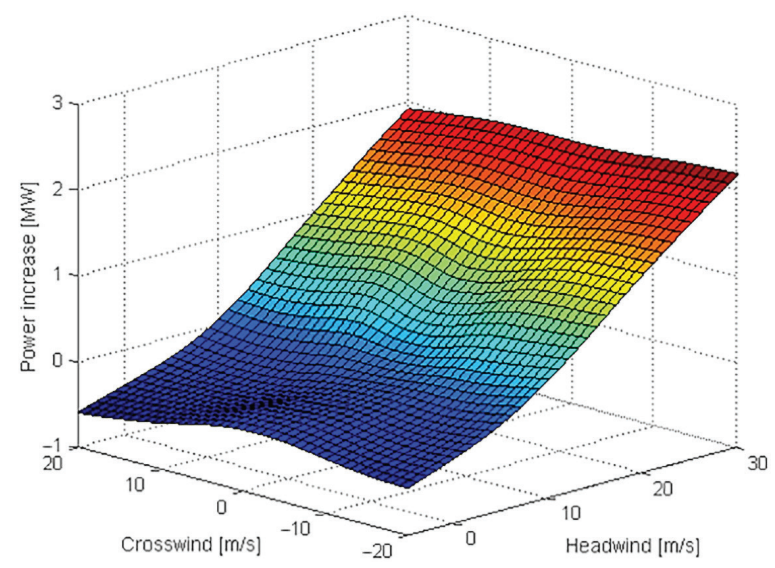

Fig. 15. Power increase due to wind at $16 \mathrm{kn}$ speed

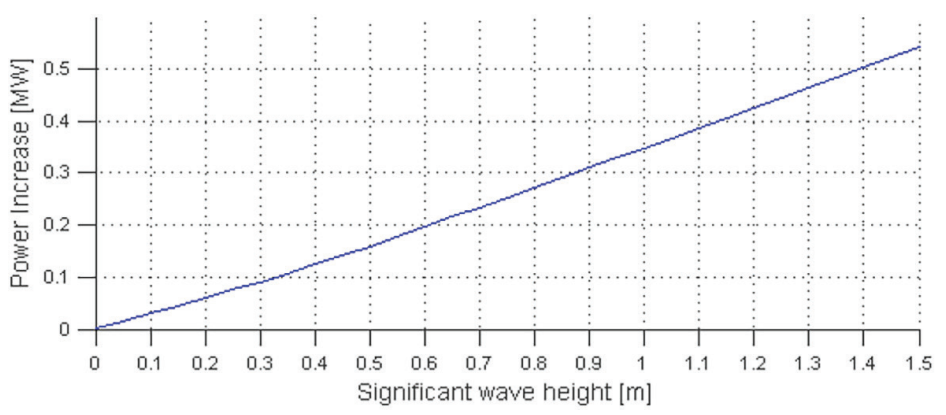

Fig. 16. Power increase due to waves at $16 \mathrm{kn}$ speed

Figure 16 illustrates the estimated effect of waves on the power consumption at $16 \mathrm{kn}$ speed. It is assumed that the power increase due to waves is proportional to the speed through water. The contributions of waves are calculated accordingly for each filtered data point and they are subtracted from the measured propulsion power values. Wave data used in the analysis is from forecasts (less than 12 hours forward), provided by one of the weather institutes, and it is synchronized based on ship's location and time.

Speed-power curves, based on a third degree polynomials are fitted to the normalized propulsion power values before and after the dry-docking. They are shown in Figure 17 along with the sea trial curve (in ideal conditions without sea margin). The speed-power performance of the ship is close to the sea trial performance, both before and after the dry-docking. The propulsion power usage is slightly lower after the dry-docking. At higher speeds the difference is more significant, although there are quite few data points with over $18 \mathrm{kn}$ speed. The difference between the fitted speed-power curves is $1-6 \%$ in the speed range from 12 to $18 \mathrm{kn}$.

For making the estimations of fuel penalty caused by decreased hull performance, the power usage of the vessel was analyzed and divided to components with the help of a regression model (Fig. 18). 


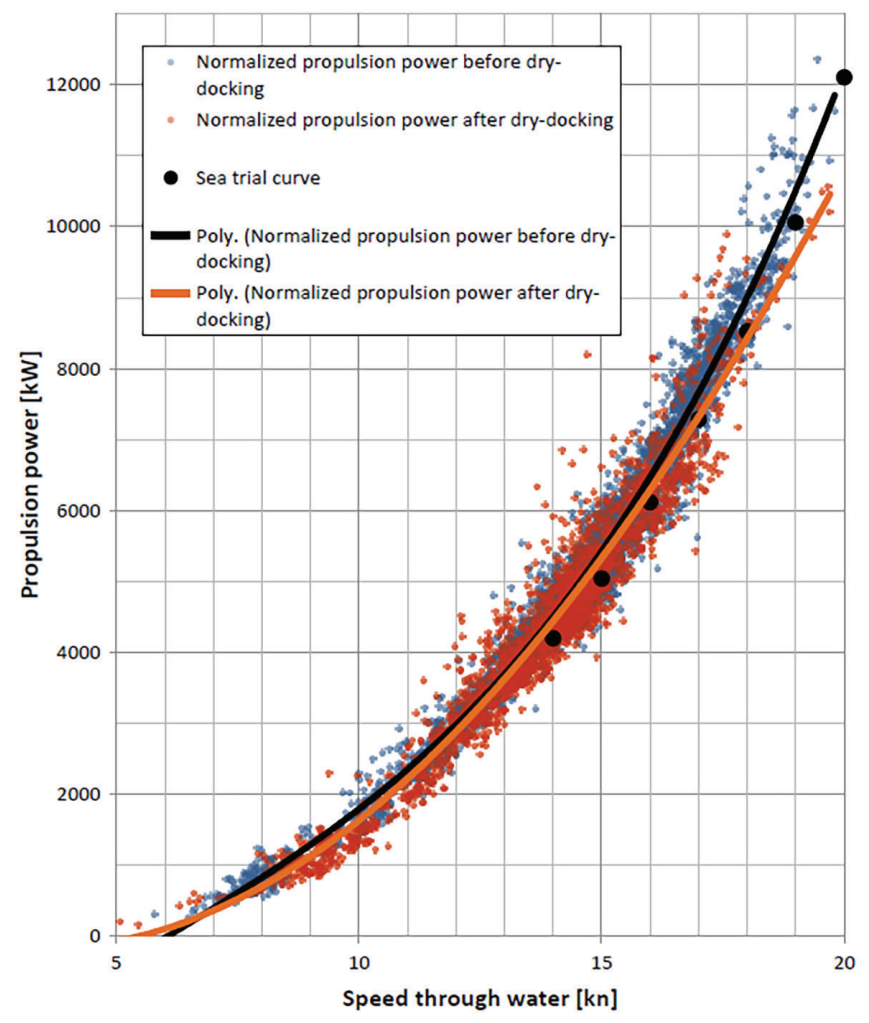

Fig. 17. Speed-power performance

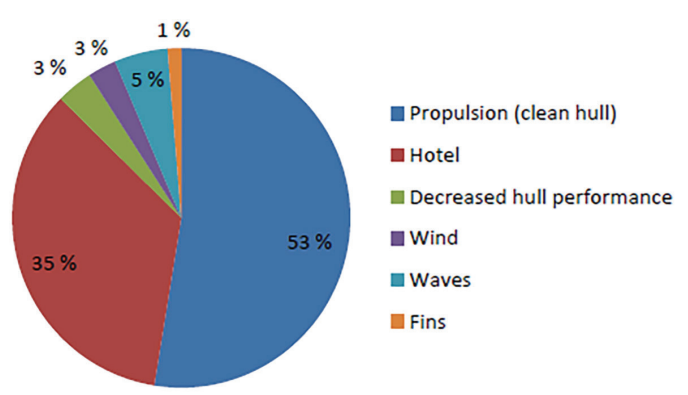

Fig. 18. Speed-power performance

Following characteristics were found in decomposition:

- average speed of the vessel during sea passages: $14.0 \mathrm{kn}$;

- average total power usage during sea passages: $8300 \mathrm{~kW}$;

- average propulsion power usage during sea passages: $5410 \mathrm{~kW}$;

- average hotel power usage during sea passages: $2890 \mathrm{~kW}$. 


\section{Concluding discussion}

This paper sustained the supposition according to which modern technologies like cloud computing, very large databases, big data and predictive analytics can be succesfuly used in knowledge creation processes for adding more business value to maritime industry. Due to the continously increasing dynamics and complexity of the maritime sector, most probably machine learning techniques will become mandatory in order for these companies to obtain competitive advantage or to survive. From our perspective, the most important contribution of this paper was to properly combine the forementioned technologies, into a unified platform architecture that was tested in normal operation conditions and which proved that indeed it is possible to gain knowledge from 'mountains' of sensor data. From our perspective, the literature lacks at this point to provide clear and well tested examples on how these technological advances in storage and computations can be properly used in real case scenarios. As mentioned previously in the paper, part of the industry is already involved in this data revolution, but still maritime management literature is very sparsed on this topic.

The architecture presented in this paper is not, by all means, related only to maritime sector. Actually, it can provide both a theoretical and a practical base to construct large automated intelligent systems that can be used in any social, technical or economical scenario that involves gathering large volumes of data for being used in business intelligence algorithms. We want to emphasize that there are two main aspects that every solution of this type should be taken into consideration: scalability and efficiency of the business intelligence algorithms. From our point of view, any platform build to help knowledge discovery, based on intelligent algorithms, will never have enough data. For example, at the beginning A.S.P.A platform started with 10 ships, than expanded to 50 and than to 160 and this number for sure will increase. Also, at this moment, we would consider extremely useful to start building also on A.I.S data and handle thousands of ships. So, we believe as a good practice to start from the beginning with the idea that data grow will never stop so we will have somehow to be prepared to scale. The second important aspect is the efficiency of the algorithms used in the business intelligence techniques applied on the set of data that we manage to have. After all, it is not enough to have data, one must used it accordingly in order to gain insights from it. The good part is that analytical platforms, as the one proposed in this paper, will provide the context for any domain specialist team to create and test as many algorithms needed, with the big advantage that it will be possible for them to validate the results based on the available collected data. Another contribution of this paper was to emphasize one aspect that usually doesn't receive enough attention when actually it should be highly sought by maritime efficiency algorithms, which is weather data. From our observations and running experiments we can state that deviations in the accuracy of weather data, especially wind and waves, could lead to very misleading results or to significant financial loses for ship voyages. This paper presented the most important data usages in the maritime sector and from the chapter where we presented some obtained results, we can notice that in case weather data values would have been corrupted, the algorithms output reliability would have dropped. If we are to discuss on the limitations and 
challenges encountered in the development of the presented platform, there are several facts that should not be ignored. One of the biggest challenges didn't came from the technological side, but from trying to understand what the shipping sector really needs, in terms of ICT development, in order to provide more valuable knowledge. Another issue that required special attention was represented by the quality of data provided by ships. There are many cases that required special handling, for example when sensors were completely broken or it sent corrupted data. A certain degree of uncertainty is also provided by the accuracy of the weather forecasts that were used. Still, for some weather parameters, like wind speed for example, it was possible to use also data transmitted by the ships. In terms of scalability, the presented architecture can be defined as being scalable, but adding more ships, will require adding also more cloud resources (Amazon in this case), which will increase the costs of operating it. One way of better managing costs is to execute anything faster. Therefore, one of our technical challenges was to improve the execution speed of each component, from data parsing to the actual ship performance analysis, having as a limitation the size and the number of the machines we could use. For this type of analytical systems, where the data flow is almost continuous, error handling mechanisms are extremely important. If some unhandled exceptions/ errors occurs, the possibility of loosing ship data should be minimal. Usually, in order to accomplish this, redundant systems are needed, which means also more allocated resources.

In terms of further research, from our perspective, it would be highly beneficial to move toward completely autonomous intelligent forecasting systems that:

- should assist all major decisions with high financial impact,

- track all day to day operations of any vessel in companies fleet,

- should analyse companies fleet performances,

- should trigger warnings if any performed/forecasted ship operation has a negative financial impact and the size of impact should be presented.

As computing resources are steadily increasing, we believe that AIS data, used in various artificial intelligence techniques, will play an important role for tomorrow shipping analysis services. For example, on-demand analysis could be requested by anyone interested on having strategic operational knowledge on any vessel or fleet of vessels in the world, his own or from the competitors.

\section{References}

Agarwal, R.; Ergun, Ö. 2008. Ship scheduling and network design for cargo routing in liner shipping, Transportation Science 42(2): 175-196. https://doi.org/10.1287/trsc.1070.0205

Bagočius, V.; Zavadskas, E. K.; Turskis, Z. 2014. Selecting a location for a liquefied natural gas terminal in the Eastern Baltic Sea, Transport 29(1): 69-74.

https://doi.org/10.3846/16484142.2014.897996

Baldi, F.; Johnson, H.; Gabrielii, C.; Andersson, K. 2014. Energy analysis of ship energy systems - the case of a chemical tanker, Energy Procedia 61: 1732-1735.

https://doi.org/10.1016/j.egypro.2014.12.200 
Bausys, R.; Zavadskas, E. K.; Kaklauskas, A. 2015. Application of neutrosophic set to multicriteria decision making by COPRAS, Journal of Economic Computation and Economic Cybernetics Studies and Research 49(2): 91-106.

Bialystocki, N.; Konovessis, K. 2016. On the estimation of ship's fuel consumption and speed curve: a statistical approach, Journal of Ocean Engineering and Science 1(2): 157-166.

https://doi.org/10.1016/j.joes.2016.02.001

Borkowski, T.; Kowalak, P.; Myśków, J. 2012. Vessel main propulsion engine performance evaluation, Journal of KONES Powertrain and Transport 19(2): 53-60.

https://doi.org/10.5604/12314005.1137890

Bowditch, N. 2015. American practical navigator: an epitome of navigation and nautical astronomy. Forgotten Books, $660 \mathrm{p}$.

Cai, Y.; Wen, Y.; Wu, L. 2014. Ship route design for avoiding heavy weather and sea conditions, International Journal on Marine Navigation and Safety of Sea Transportation 8(4): 551-556. https://doi.org/10.12716/1001.08.04.09

Chen, C.; Shiotani, S.; Sasa, K. 2013. Numerical ship navigation based on weather and ocean simulation, Ocean Engineering 69: 44-53. https://doi.org/10.1016/j.oceaneng.2013.05.019

Clarksons PLC. 2015. Preliminary results for the 12 months ended 31 December 2014. 21 p.

Fremont, A. 2007. Global maritime networks: the case of Maersk, Journal of Transport Geography 15(6): 431-442. https://doi.org/10.1016/j.jtrangeo.2007.01.005

Gandomi, A.; Haider, M. 2015. Beyond the hype: big data concepts, methods, and analytics, International Journal of Information Management 35(2): 137-144.

https://doi.org/10.1016/j.ijinfomgt.2014.10.007

Harati-Mokhtari, A.; Wall, A.; Brooks, P.; Wang, J. 2007. Automatic identification system (AIS): data reliability and human error implications, The Journal of Navigation 60(3): 373-389. https://doi.org/10.1017/S0373463307004298

Hellström, T. 2003. Three levels of fuel optimization at sea, in 2nd International EuroConference on Computer and IT Applications in the Maritime Industries (COMPIT'03), 14-17 May 2003, Hamburg, Germany, 321-335.

Hoffschildt, M.; Bidlot, J.-R.; Hansen, B.; Janssen, P. A. E. M. 1999. Potential benefit of ensemble forecasts for ship routing. ECMWF Technical Memorandum No 287. 28 p.

Johnson, H.; Andersson, K. 2016. Barriers to energy efficiency in shipping, WMU Journal of Maritime Affairs 15(1): 79-96. https://doi.org/10.1007/s13437-014-0071-z

Johnson, H.; Styhre, L. 2015. Increased energy efficiency in short sea shipping through decreased time in port, Transportation Research Part A: Policy and Practice 71: 167-178. https://doi.org/10.1016/j.tra.2014.11.008

Kayano, J.; Yabuki, H.; Sasaki, N.; Hiwatashi, R. 2013. A study on the propulsion performance in the actual sea by means of full-scale experiments, International Journal on Marine Navigation and Safety of Sea Transportation 7(4): 521-526. https://doi.org/10.12716/1001.07.04.07

Keefe, P. 2014. Optimize performance via data analytics, Maritime Professional (1): 50-54.

Koga, S. 2015. Major challenges and solutions for utilizing big data in the maritime industry: MSc Dissertation. World Maritime University, Malmö, Sweden. 100 p.

Lazakis, I.; Dikis, K.; Michala, A. L.; Theotokatos, G. 2016. Advanced ship systems condition monitoring for enhanced inspection, maintenance and decision making in ship operations, Transportation Research Procedia 14: 1679-1688. https://doi.org/10.1016/j.trpro.2016.05.133

Lau, R. Y. K.; Zhao, J. L.; Chen, G.; Guo, X. 2016. Big data commerce, Information \& Management 53(8): 929-933. https://doi.org/10.1016/j.im.2016.07.008 
Lorange, P.; Fjeldstad, Ø. D. 2010. Redesigning organizations for the 21 st century: lessons from the global shipping industry, Organizational Dynamics 39(2): 184-193.

https://doi.org/10.1016/j.orgdyn.2010.01.007

Lušić, Z.; Kos, S. 2013. Ranking of sailing routes according to the potential number of groundings, Transport 28(3): 295-301. https://doi.org/10.3846/16484142.2013.831374

Mason, R.; Nair, R. 2013. Supply-side strategic flexibility capabilities in container liner shipping, The International Journal of Logistics Management 24(1): 22-48.

https://doi.org/10.1108/IJLM-05-2013-0053

Miah, S. J.; Vu, H. Q.; Gammack, J.; McGrath, M. 2017. A big data analytics method for tourist behaviour analysis, Information \& Management 54(6): 771-785.

https://doi.org/10.1016/j.im.2016.11.011

Mihanović, L.; Ristov, P.; Belamarić, G. 2016. Use of new information technologies in the maintenance of ship systems, Scientific Journal of Maritime Research 30(1): 38-44.

Motte, R. 1972. Weather routeing of ships. Littlehampton Book Services Ltd. 160 p.

Padhy, C. P.; Sen, D.; Bhaskaran, P. K. 2008. Application of wave model for weather routing of ships in the North Indian Ocean, Natural Hazards 44(3): 373-385.

https://doi.org/10.1007/s11069-007-9126-1

Panayides, P. M.; Polyviou, M. 2011. The effect of ports' logistics attributes and services on the business and supply chain performance of shipping firms, International Journal of Shipping and Transport Logistics (IJSTL) 3(4): 430-453. https://doi.org/10.1504/IJSTL.2011.041136

Panayides, P. M.; Wiedmer, R. 2011. Strategic alliances in container liner shipping, Research in Transportation Economics 32(1): 25-38. https://doi.org/10.1016/j.retrec.2011.06.008

Panigrahi, J. K.; Padhy, C. P.; Sen, D.; Swain, J.; Larsen, O. 2012. Optimal ship tracking on a navigation route between two ports: a hydrodynamics approach, Journal of Marine Science and Technology 17(1): 59-67. https://doi.org/10.1007/s00773-011-0116-3

Paulauskas, V.; Paulauskas, D.; Maksimavičius, R.; Jonkus, M. 2014. Hydrodynamic interactions between ships in narrow channels, Transport 29(2): 212-216.

https://doi.org/10.3846/16484142.2014.931886

Perera, L. P.; Mo, B. 2016. Data analysis on marine engine operating regions in relation to ship navigation, Ocean Engineering 128: 163-172. https://doi.org/10.1016/j.oceaneng.2016.10.029

Ristov, P.; Perić, M.; Tomas, V. 2014. The implementation of cloud computing in shipping companies, Scientific Journal of Maritime Research 28: 80-87.

Robinson, R. 2004. Liner shipping strategy, network structuring and competitive advantage: a chain systems perspective, Research in Transportation Economics 12: 247-289.

https://doi.org/10.1016/S0739-8859(04)12008-8

Sahasrabuddhe, D. V.; Jamsandekar, P. P. 2015. Data structure for representation of big data of weather forecasting: a review, International Journal of Computer Science Trends and Technology (IJCST) 3(6): 48-56.

Sasaki, N.; Tsujimoto, M.; Kuroda, M.; Sogihara, N.; Ichinose, Y.; Usui, N.; Ueno, M.; Fujiwara, T.; Hoshino, K.; Kawanami, Y.; Ohmatsu, S.; Shibata, K. 2010. Development of ship performance index: 10 mode at sea, Papers of National Maritime Research Institute 9(4): 219-264 (in Japanese).

Shiotani, S. 2002. Experimental verification of simulation for navigation utilizing current sailing, Journal of the Kansai Society of Naval Architects, Japan (238): 205-213.

Snyder, B.; Bosanac, D.; Davies, R. 2011. ActiveMQ in action. Manning Publications. 375 p.

Soda, T.; Shiotani, S.; Makino, H.; Shimada, Y. 2012. Research on ship navigation in numerical simulation of weather and ocean in a bay, International Journal on Marine Navigation and Safety of Sea Transportation 6(1): 19-25. 
Statista GmbH. 2016. Number of ships in the world merchant fleet as of january 1, 2016, by type [online], [cited 25 February 2017]. Available from Internet: https://www.statista.com/statistics/264024/number-of-merchant-ships-worldwide-by-type

Stojaković, M.; Twrdy, E. 2016. A decision support tool for container terminal optimization within the berth subsystem, Transport 31(1): 29-40. https://doi.org/10.3846/16484142.2014.994226

Tongzon, J.; Chang, Y.-T.; Lee, S.-Y. 2009. How supply chain oriented is the port sector?, International Journal of Production Economics 122(1): 21-34. https://doi.org/10.1016/j.ijpe.2009.03.017

Traut, M.; Gilbert, P.; Walsh, C.; Bows, A.; Filippone, A.; Stansby, P.; Wood, R. 2014. Propulsive power contribution of a kite and a Flettner rotor on selected shipping routes, Applied Energy 113: 362-372. https://doi.org/10.1016/j.apenergy.2013.07.026

Tsujimoto, M.; Tanizawa, K. 2006. Development of a weather adaptive navigation system considering ship performance in actual seas, in 25th International Conference on Offshore Mechanics and Arctic Engineering, 4-9 June 2006, Hamburg, Germany, 2: 413-421.

https://doi.org/10.1115/OMAE2006-92376

Tuljak-Suban, D. 2017 Competition or cooperation in a hub and spoke-shipping network: the case of the North Adriatic container terminals, Transport (in press).

https://doi.org/10.3846/16484142.2016.1261368

Tzannatos, E.; Tselentis, B.; Corres, A. 2016. An inland waterway freight service in comparison to land-based alternatives in South-Eastern Europe: energy efficiency and air quality performance, Transport 31(1): 119-126. https://doi.org/10.3846/16484142.2016.1129647

WMO. 1995. Manual on Codes International Codes. Volume I.1. Part A - Alphanumeric Codes. WMO No. 306. World Meteorological Organization (WMO). 504 p.

Xia, H.; Shiotani, S.; Kobayashi, E.; Wakabayashi, N. 2006. Estimation of ship's course for sailing on route by navigation simulation in coastal water, The Journal of Japan Institute of Navigation 115: 51-57.

Xia, H.; Shiotani, S.; Kobayashi, E.; Wakabayashi, N. 2005. A study of weather routing considering real time data of weather and ocean for sailing ship in coastal sea area - basic simulation of ship positioning by ship maneuvring and experiment by a real ship, Journal of the Kansai Society of Naval Architects, Japan 243: 159-166 (in Japanese).

Yokoi, T.; Shoji, R.; Tamaru, H.; Yabuki, H. 2010. A mechanism on parallel processing to numerical weather prediction for weather routing, in Proceedings of Asia Navigation Conference 2009, 19-21 November, 2009, Shizuoka, Japan (in Japanese).

Zhang, J.; Huang, L. 2007. Optimal ship weather routing using isochrone method on the basis of weather changes, in International Conference on Transportation Engineering 2007, 22-24 July, 2007, Chengdu, China, 2650-2655. https://doi.org/10.1061/40932(246)435

Zhang, Q.; Zeng, Q.; Yang, H. 2016. A lexicographic optimization approach for berth schedule recovery problem in container terminals, Transport 31(1): 76-83.

https://doi.org/10.3846/16484142.2016.1125387 
Dragos Sebastian CRISTEA. Assistant Professor of Informatics for Economics at Faculty of Economics and Business Administration, Dunarea de Jos University of Galati, Romania. He has successfully participated and coordinated national and international research projects. He collaborated with several large IT companies as a software architect. His research interest includes software architectures, distributed systems, business intelligence, machine learning, etc.

Liliana Mihaela MOGA. Professor of Management Information Systems, Habilitate at Faculty of Economics and Business Administration, Dunarea de Jos University of Galati, Romania. Member of Editororial Boards for International Data Bases indexed Journals and of the Organizing Committee of International Conferences. Her research interest includes management information systems, traceability, technology adoption, management, etc. She was a Visiting Professor at universities from China and Turkey, and has successfully conducted national and international sponsored research projects and grants.

Mihaela NECULITA. Professor of Economics, Department of Economics, Faculty of Economics and Business Administration, Dunarea de Jos University of Galati, Romania. Member of professional and academic organizations and organizing committees of international conferences. She is Visiting Professor at universities from China and Turkey and member in teams of national and international research projects. Her interests are in economics and European policies in different areas including transports.

Olegas PRENTKOVSKIS. Professor of Technological Sciences, Dean of the Faculty of Transport Engineering, Vilnius Gediminas Technical University, Lithuania. Editor-in-Chief of the journal Transport. His research interest includes transport engineering, traffic safety, transportation, logistics, transport management, etc. He is a Visiting Professor at various universities in Latvia, Ukraine, Russia and has successfully participated in national sponsored research projects and grants.

Khalil MD NOR. Professor at the University of Technology Malaysia. He is a member of the Business Administration Department, Faculty of Management. His research interests are in the area of knowledge management, technology adoption and e-commerce.

Abbas MARDANI. Senior lecturer (PhD) in faculty of management at the University of Technology Malaysia (UTM). He received $\mathrm{PhD}$ in field of philosophy of management (operation and production management) from UTM (2015), the bachelor's degree in industrial management (2007) and master's degree in industrial management (2009), (operation and production management) in Iran. His research interests include multiple criteria decision making, fuzzy sets theory, operation management, sustainable and renewable energies, quality management, sustainable development, SCM, sustainable SCM. 